\title{
Determinants of Fruit and Vegetables Intake among Secondary School Pupils in the City of Bobo-Dioulasso (Burkina Faso): A Cross-Sectional Study
}

\author{
Téné Marceline Yaméogo ${ }^{1,2^{*}}$, Issiaka Sombié ${ }^{1}$, Carole Gilberte Kyelem ${ }^{1,2}$, Oumar Guira ${ }^{3}$, \\ Djingri Lankoandé ${ }^{2}$, Bazoumana Coulibali ${ }^{1}$, Mireille Marie Déborah Tapsoba ${ }^{1}$, \\ Alassane Ilboudo², Aimée Sankaye-Lagom Kissou1,2, Abraham Bagbila², \\ Apollinaire Sawadogo ${ }^{2,3}$, Macaire Sampawinde Ouédraogo1,2, Youssouf Joseph Drabo ${ }^{3}$
}

${ }^{1}$ INSSA, Université Nazi Boni, Bobo-Dioulasso, Burkina Faso

${ }^{2} \mathrm{CHU}$ Souro Sanon, Bobo-Dioulasso, Burkina Faso

${ }^{3}$ UFR-SDS, Université Joseph Ki-Zerbo, Ouagadougou, Burkina Faso

Email: *teneline@gmail.com

How to cite this paper: Yaméogo, T.M., Sombié, I., Kyelem, C.G., Guira, O., Lankoandé, D., Coulibali, B., Tapsoba, M.M.D., Ilboudo, A., Kissou, A.S.-L., Bagbila, A., Sawadogo, A., Ouédraogo, M.S. and Drabo, Y.J. (2018) Determinants of Fruit and Vegetables Intake among Secondary School Pupils in the City of Bobo-Dioulasso (Burkina Faso): A Cross-Sectional Study. Open Journal of Internal Medicine, 8, 1-9. https://doi.org/10.4236/ojim.2018.81001

Received: December 8, 2017 Accepted: January 19, 2018

Published: January 22, 2018

Copyright $\odot 2018$ by authors and Scientific Research Publishing Inc. This work is licensed under the Creative Commons Attribution International License (CC BY 4.0).

http://creativecommons.org/licenses/by/4.0/

\begin{abstract}
According to WHO, eating at least five portions of fruit and vegetables a day at an early age is protective against cancers, cardiovascular diseases and diabetes. The purpose of this study was to determine among secondary school pupils in the city of Bobo-Dioulasso, the level of observation of this recommendation and the associated factors. Methods: This was a cross-sectional study conducted from March to April 2016, among secondary school pupils in $1^{\text {st }}$ Form, $4^{\text {th }}$ Form and $7^{\text {th }}$ Form of public and private secondary schools. The diet survey methods were the recalling of the last 24 hours associated with intake frequency questionnaire. An intake of less than one fruit (or a slice of a big fruit) per day and for vegetables, less than one portion of raw or cooked vegetables per day was considered insufficient. Results: A total of 1993 pupils were surveyed. The mean age was $17.5 \pm 3.6$ years and the sex ratio $0.7 ; 75.4 \%$ and $90.0 \%$ of pupils had insufficient daily intake of fruit and vegetables respectively. The determinants of this consumption deficiency were: Sex (male, $\mathrm{OR}=1.7(1.3-2.2))$, secondary school (public, $\mathrm{OR}=1.6(1.3-2.0))$, class $\left(4^{\text {th }}\right.$ Form, $\mathrm{OR}=2.5(1.5-4.2) / 7^{\text {th }}$ Form, $\left.\mathrm{OR}=3.7(2.7-5.1)\right)$, the mother (thin build, $\mathrm{OR}=3.2(2.0-5.3) /$ overweight/obesity, $\mathrm{OR}=2.8(1.6-4.7))$ and physical inactivity $(\mathrm{OR}=1.5(1.2-2.0))$. Conclusion: The promotion of a healthy diet among secondary school pupils should take into account the type of school, sex, educational level, physical activity and mothers' influence.
\end{abstract}




\section{Keywords}

Fruit and Vegetables Intake, Cardiovascular Prevention, Young Subject

\section{Introduction}

Unhealthy dietary and physical behaviors are at the root of obesity epidemic and cardiovascular diseases, including even children [1] [2]. In Africa, the number of overweight/obese children has increased from 4 to 9 million between 1990 and 2016 [3]. In Burkina Faso, the prevalence of overweight/obesity with school children was $8.6 \%$ in 2010 [4]. Prevention strategies for these diseases, apart from regular physical activity, require a healthy diet; one of the leading recommendations is the daily intake of at least $400 \mathrm{~g}$ per day, or at least 5 daily portions of fruit and vegetables [1] [2]. Children and adolescents constitute a prime target. As a matter of fact, fruit and vegetables, rich in vitamins, minerals and fibers, have a favorable effect on health and a protective role against cancers, cardiovascular diseases and diabetes [1] [2] [5]. In Burkina Faso, a study among schoolchildren reports that during the week preceding the study, $25 \%$ of children had not eaten fruit [6]. The national STEP survey revealed an insufficient intake of fruit and vegetables for $95 \%$ of adults (unpublished data). Should we fear such a level of intake among adolescents? The purpose of our study was to determine the frequency and the individual determinants of insufficient intake of fruit and vegetables among secondary school pupils in urban areas in order to undertake an appropriate promotion of good diet habits in this segment of the population.

\section{Methods}

It was a cross-sectional analytical study, which was conducted from March to April 2016, among pupils in $1^{\text {st }}$ Form, $4^{\text {th }}$ Form and $7^{\text {th }}$ Form of public and private secondary schools in the city of Bobo-Dioulasso in order to determine the prevalence of cardiovascular risk factors. The calculation parameters of the sample were as follows: prevalence $8 \%$ (prevalence of overweight/obesity in the schools of Burkina Faso [4], accuracy 3\%, alpha error 5\% (CI 95\%), N =65,765 pupils, a cluster effect 2 . The calculated sample was 1890 pupils, distributed into 630 pupils per class group of $1^{\text {st }}$ Form, $4^{\text {th }}$ Form and $7^{\text {th }}$ Form in order to detect a possible gradient according to the educational level.

The diet survey methods were a recalling of the last 24 hours associated with intake frequency questionnaire.

The informed variables were: food and beverages consumed in the past 24 hours, the weekly intake rate of vegetables (unit $=1$ portion) and fruit (unit $=1$ fruit or 1 slice of large fruit) available as follows: at least 3 times per day, every day/1 time per day, every day/3 - 4 times per week/1 - 2 times per week/Rarely/ Never. 
Given the general context of low intake of fruits and vegetables in Burkina Faso (the national survey STEP in 2013 reported an insufficient intake of fruit and vegetables for $95 \%$ of adults, while Daboné noted that a quarter of schoolchildren did not consume any fruit the previous 7 days [6]), we have chosen a minimum intake threshold of 1 fruit or 1 portion of vegetables per day. So, an intake of less than one fruit (or a slice of a big fruit) per day, and for vegetables, less than one portion of raw or cooked vegetables per day, was considered insufficient. The factors associated with this insufficient intake will serve as a basis for developing an intervention strategy by step to ultimately reach the recommendation for 5 fruits and vegetables per day.

The classification criteria of mother and father's build were based on an iconography showing 4 morphotypes: thin, normal, overweight and obese. Pupils had to check the morphotype corresponding to that of their mother and father.

The classification criteria of body mass index (BMI) are those of the International Obesity Task Force (IOTF) which defines for each sex and at each age a threshold value of overweight and obesity [7] [8].

Through logistic regression method, individual socio-demographic and clinical factors, significantly associated with insufficient fruit and vegetable intake at $5 \%$ of significance level, were identified.

The overall project of this study was approved by Burkina Faso's National Ethics Committee. Authorizations from the Regional Director of Secondary Education and from Secondary School Administrations were obtained for the survey. An informed consent form attached to an information leaflet was sent to parents before the survey. Only pupils whose parents gave their consent by signing the consent form were interviewed. The data were also processed in respect of the anonymity of the respondents.

\section{Results}

A total of 1993 pupils were surveyed: 649 in $1^{\text {st }}$ Form, 673 in $4^{\text {th }}$ Form and 671 in $7^{\text {th }}$ Form.

\subsection{General Characteristics of Pupils}

The mean age was $17.5 \pm 3.6$ years. The mean age per class group was $13.6 \pm 1.5$ years in $1^{\text {st }}$ Form, $17.5 \pm 1.8$ years in $4^{\text {th }}$ Form, and $21.3 \pm 2.0$ years in $7^{\text {th }}$ Form.

More than half of the pupils were female, $56.6 \%(n=1128)$, that means a sex ratio of 0.8 .

\subsection{Characteristics of Fruit Intake}

Only $24.6 \%$ of pupils consumed at least 1 fruit per day (corresponding to those who consumed fruit at least 3 times per day, every day and once per day, every day).

The frequency of insufficient fruit intake was $75.4 \%(n=1503)$.

In multivariate analysis, sex (male), type of secondary school (public), educa- 
tional level ( $4^{\text {th }}$ Form or $7^{\text {th }}$ Form $)$ and non-practice of a regular physical activity were factors independently associated with this insufficient intake (Table 1). We notice that this intake deficiency worsened over the course of classes (years).

\subsection{Characteristics of Vegetable Intake}

Only $10.0 \%$ of pupils consumed at least 1 portion of vegetables per day.

The frequency of insufficient vegetable intake was $90.0 \%(\mathrm{n}=1793)$.

Multivariate analysis showed that educational level ( $4^{\text {th }}$ Form and $7^{\text {th }}$ Form) and mother's build (thin or overweight/obesity) were factors independently associated with insufficient intake (Table 2).

\section{Discussion}

From 7 to $9 / 10$ pupils had an insufficient intake of fruit and vegetables. These results, although lower than the results of STEPS survey among adults in Burkina, are nonetheless alarming. They are in the order of previous data for secondary school pupils in other countries of our sub region [9] [10]. In France in 2010, $63.7 \%$ of adolescents declared that they did not consume fruit every day, $62.9 \%$ for vegetables.

The main modifiable factors of these diet habits included educational level and mothers' influence.

Many studies have shown that mothers' influence is associated with healthy diet behaviors of their children [11] [12] [13]. In Burkina, like everywhere in the world, they are a landmark for their children; their food choices, their methods of preparation, their encouragement to consume them are all factors that affect the food choices of their family members.

Many individual determinants influence diet behavior [13] [14] [15]. Among other things, there is the physiological state, especially age and gender.

In our study, $4^{\text {th }}$ Form and $7^{\text {th }}$ Form pupils consumed fruit and vegetables less often than those who were significantly younger (mean age $=13.6 \pm 1.5$ years in $1^{\text {st }}$ Form against $17.5 \pm 1.8$ years) in $4^{\text {th }}$ Form and $21.3 \pm 2.0$ years in $7^{\text {th }}$ Form). It was the same for boys compared to girls. $1^{\text {st }}$ Form pupils in pre-adolescence are still influenced by their mothers. The educational level is a determinant reported by Peltzer, who associated higher education with insufficient intake of fruit and vegetables [16]. We also found a decline in this intake related to the level of education, with lower intake in upper classes; pupils are bigger, with an affirmation of their food choices.

Food preferences are also reported as determinant of diet habits [13] [14] [15]. For example, "not liking vegetables" is one of the main predictive factors of fruit and vegetables intake among children [17]. Cultural factors are not left behind in food choices foods [18] [19] [20]. Food choices inspired by native cultural values do not always correspond to the "western" perception of the nutritional value of foods. In our region, the traditional composition of set meals does not specify vegetables or fruit in the form of starter and/or dessert. 
Table 1. Determinants of insufficient daily intake of fruit among pupils in $1^{\text {st }}$ Form, $4^{\text {th }}$ Form and $7^{\text {th }}$ Form of public and private secondary schools in the city of Bobo-Dioulasso (Burkina Faso).

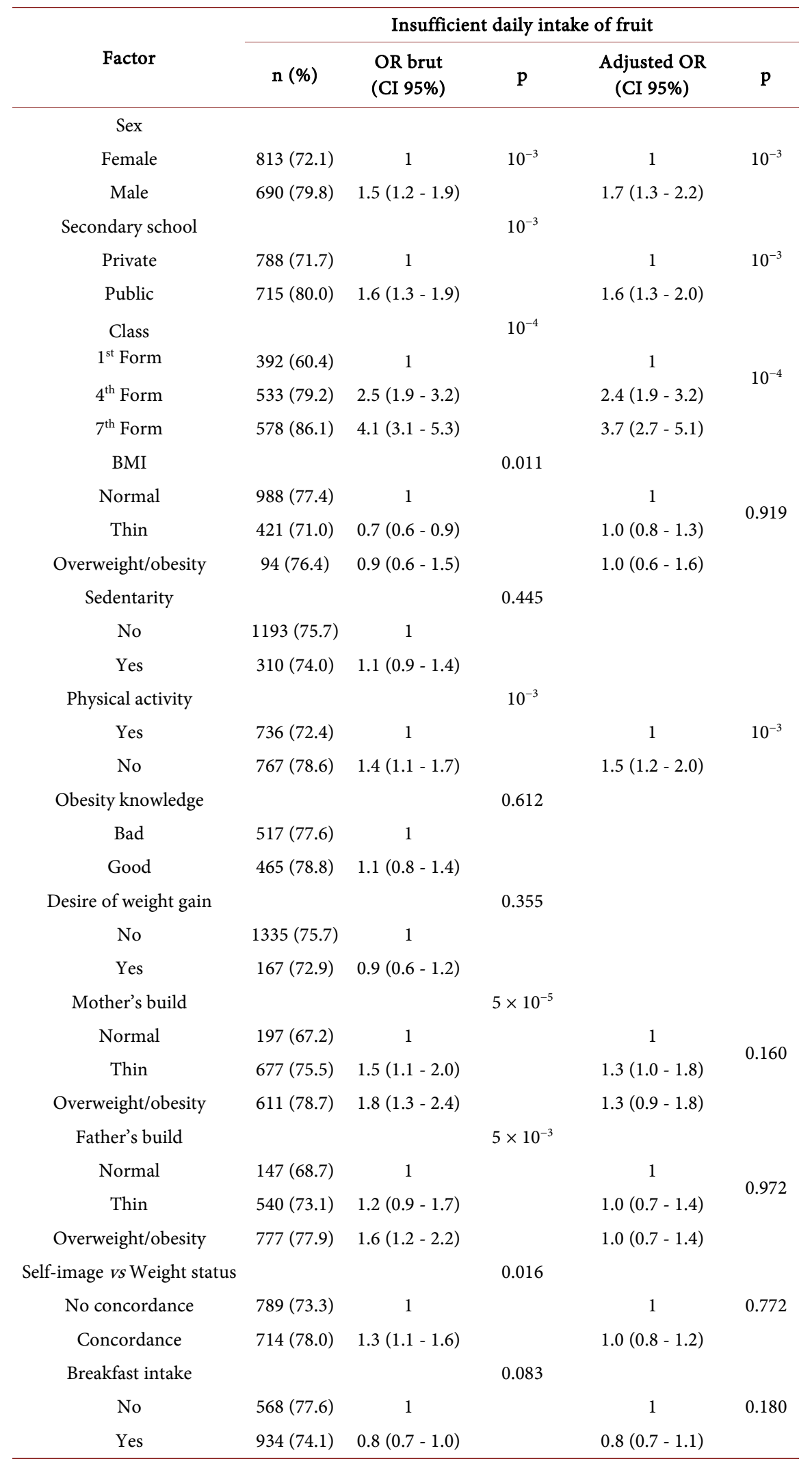


Table 2. Determinants of insufficient daily intake of vegetables among pupils in $1^{\text {st }}$ Form, $4^{\text {th }}$ Form and $7^{\text {th }}$ Form of public and private secondary schools in the city of Bobo-Dioulasso (Burkina Faso).

\begin{tabular}{|c|c|c|c|c|c|}
\hline \multirow[b]{2}{*}{ Factor } & \multicolumn{5}{|c|}{ Insufficient daily intake of vegetables } \\
\hline & n (\%) & $\begin{array}{l}\text { OR brut } \\
\text { (CI 95\%) }\end{array}$ & $\mathrm{p}$ & $\begin{array}{c}\text { Ajusted OR } \\
\text { (CI 95\%) }\end{array}$ & $\mathrm{p}$ \\
\hline \multicolumn{6}{|l|}{ Sex } \\
\hline Female & $1004(89.0)$ & 1 & 0.105 & & \\
\hline Male & $789(91.2)$ & $1.3(0.9-1.7)$ & & & \\
\hline \multicolumn{6}{|l|}{ Secondary school } \\
\hline Private & $806(90.2)$ & 1 & 0.797 & & \\
\hline Public & $987(89.8)$ & $0.96(0.7-1.3)$ & & & \\
\hline \multicolumn{6}{|l|}{ Class } \\
\hline $1^{\text {st }}$ Form & $544(83.8)$ & 1 & \multirow{3}{*}{$10^{-4}$} & 1 & \multirow{3}{*}{$9 \times 10^{-4}$} \\
\hline $4^{\text {th }}$ Form & $615(91.4)$ & $2.0(1.4-2.9)$ & & $2.5(1.5-4.2)$ & \\
\hline $7^{\text {th }}$ Form & $634(94.5)$ & $3.3(2.2-4.9)$ & & $2.6(1.3-5.2)$ & \\
\hline \multicolumn{6}{|l|}{ BMI } \\
\hline Normal & $1162(91.0)$ & 1 & \multirow{2}{*}{0.123} & & \\
\hline Thin & $522(88.0)$ & $0.7(0.5-1.0)$ & & & \\
\hline Overweight/obesity & $109(88.6)$ & $0.8(0.4-1.4)$ & & & \\
\hline \multicolumn{6}{|l|}{ Sedentarity } \\
\hline No & $1414(89.8)$ & 1 & \multirow[t]{2}{*}{0.708} & & \\
\hline Yes & $379(90.5)$ & $0.9(0.6-1.3)$ & & & \\
\hline \multicolumn{6}{|l|}{ Physical activity } \\
\hline No & $885(90.7)$ & 1 & \multirow[t]{2}{*}{0.301} & & \\
\hline Yes & $908(89.3)$ & $0.9(0.6-1.1)$ & & & \\
\hline \multicolumn{6}{|l|}{ Obesity knowledge } \\
\hline Bad & $590(88.6)$ & 1 & \multirow[t]{2}{*}{0.067} & & \\
\hline Good & $541(91.7)$ & $1.4(1.0-2.1)$ & & & \\
\hline \multicolumn{6}{|l|}{ Desire of weight gain } \\
\hline No & $1587(90.0)$ & 1 & \multirow[t]{2}{*}{0.814} & & \\
\hline Yes & $205(89.5)$ & $0.9(0.6-1.5)$ & & & \\
\hline \multicolumn{6}{|l|}{ Mother's build } \\
\hline Normal & $242(82.6)$ & 1 & \multirow{2}{*}{$10^{-4}$} & 1 & \multirow{2}{*}{$10^{-4}$} \\
\hline Thin & $817(91.1)$ & $0.46(0.3-0.7)$ & & $3.2(2.0-5.3)$ & \\
\hline Overweight/obesity & $709(91.4)$ & & & $2.8(1.6-4.7)$ & \\
\hline \multicolumn{6}{|l|}{ Father's build } \\
\hline Normal & $179(83.6)$ & 1 & \multirow{2}{*}{$4 \times 10^{-3}$} & 1 & \multirow{2}{*}{0.875} \\
\hline Thin & $669(90.5)$ & $1.9(1.2-2.9)$ & & $1.0(0.5-1.9)$ & \\
\hline Overweight/obesity & $909(91.2)$ & $2.0(1.3-3.1)$ & & $0.9(0.5-1.7)$ & \\
\hline \multicolumn{6}{|c|}{ Self-image $v s$ weight status } \\
\hline No concordance & $967(89.8)$ & 1 & 0.774 & & \\
\hline Concordance & $826(90.2)$ & $1.0(0.8-1.4)$ & & & \\
\hline \multicolumn{6}{|l|}{ Breakfast intake } \\
\hline No & $669(91.4)$ & 1 & 0.117 & & \\
\hline Yes & $1124(89.2)$ & $0.8(0.6-1.1)$ & & & \\
\hline
\end{tabular}


Vegetables are usually incorporated, in small or large quantities, in the cooking of the main meal; fruit are consumed outside the meals in the form of a snack. In the area of Bobo-Dioulasso, fruit and vegetables are relatively available and cheap according to their season. However, their affordability is variable within the population [6]. Thus, diet behaviors considered unfavorable were associated with unfavorable socio-economic characteristics [6] [9] [21] [22]. In our study, we have noticed that pupils enrolled in public secondary schools had a lower fruit intake compared to their mates in private secondary schools.

Suggestions based on the findings of this study could be, as a priority, the sensitization of mothers on the nutritional and preventive values of fruit and vegetables, the introduction of a teaching module on nutritional and preventive values of fruit and vegetables from $1^{\text {st }}$ Form classes and then rehearsal of the module in $3^{\text {rd }}$ Form and $6^{\text {th }}$ Form classes, the selling of fruits at subsidized prices in secondary schools and in public schools in particular.

The purpose of this study was to throw light on the individual behaviors of pupils in order to draw lessons for cardiovascular prevention. Thus, the collective determinants of diet behavior (environmental, social, and economic) that go beyond the scope of our study have not been studied, limiting this study. However, their place is essential in a comprehensive prevention program. Another limit could be the inclusion of pupils in examination classes ( $4^{\text {th }}$ and $7^{\text {th }}$ Forms) in the study.

\section{Conclusion}

This study showed that 7 to 9 pupils out of 10 had a highly inadequate daily intake of fruit and vegetables in the city of Bobo-Dioulasso. The main determinants of these diet habits were the type of school, sex, educational level, and mothers' influence. Activities promoting healthy diet among secondary school pupils should take this into account.

\section{References}

[1] Lichtenstein, A.H., Appel, L.J., Brands, M., Carnethon, M., Daniels, S., Franch, H.A., et al. (2006) Diet and Lifestyle Recommendations Revision 2006: A Scientific Statement From the American Heart Association Nutrition Committee. Circulation, 114, 82-96. https://doi.org/10.1161/CIRCULATIONAHA.106.176158

[2] WHO. Promoting Fruit and Vegetable Consumption around the World. http://www.who.int/dietphysicalactivity/fruit/en/

[3] WHO. Facts and Figures on Childhood Obesity. http://www.who.int/end-childhood-obesity/facts/en/

[4] Kouéta, F., Dao, L., Dao, F., Djekompté, S., Sawadogo, J., Diarra, Y., et al. (2011) Factors Associated with Overweight and Obesity in Children in Ouagadougou (Burkina Faso). Sante, 21, 227-231.

[5] Darnton-Hill, I., Nishida, C. and James, W.P.T. (2004) A Life Course Approach to Diet, Nutrition and the Prevention of Chronic Diseases. Public Health Nutrition, 7, 101-21. https://doi.org/10.1079/PHN2003584

[6] Poor Nutritional Status of Schoolchildren in Urban and Peri-Urban Areas of Oua- 
gadougou (Burkina Faso). PubMed - NCBI.

https://www.ncbi.nlm.nih.gov/pubmed/?term=Poor+nutritional+status+of+schoolc hildren+in+urban+and+peri-urban+areas+of+Ouagadougou

[7] Cole, T.J., Bellizzi, M.C., Flegal, K.M. and Dietz, W.H. (2000) Establishing a Standard Definition for Child Overweight and Obesity Worldwide: International Survey. $B M J, 320,1-6$.

[8] Monasta, L., Lobstein, T., Cole, T.J., Vignerová, J. and Cattaneo, A. (2011) Defining Overweight and Obesity in Pre-School Children: IOTF Reference or WHO Standard? Obesity Reviews, 12, 295-300. https://doi.org/10.1111/j.1467-789X.2010.00748.x

[9] Doku, D., Koivusilta, L., Raisamo, S. and Rimpelä, A. (2013) Socio-Economic Differences in Adolescents' Breakfast Eating, Fruit and Vegetable Consumption and Physical Activity in Ghana. Public Health Nutrition, 16, 864-872. https://doi.org/10.1017/S136898001100276X

[10] Eme, P.E. and Onuoha, O.N. (2014) Prevalence of Overweight and Obesity among Adolescents in Secondary Schools in Abia State, Nigeria. Annual Research \& Review in Biology, 5, 433-438. https://doi.org/10.9734/ARRB/2015/9919

[11] Larson, N.I., Neumark-Sztainer, D., Hannan, P.J. and Story, M. (2007) Family Meals during Adolescence Are Associated with Higher Diet Quality and Healthful Meal Patterns during Young Adulthood. Journal of the American Dietetic Association, 107, 1502-1510. https://doi.org/10.1016/j.jada.2007.06.012

[12] Nicklas, T.A., Baranowski, T., Baranowski, J.C., Cullen, K., Rittenberry, L. and Olvera, N. (2001) Family and Child-Care Provider Influences on Preschool Children's Fruit, Juice, and Vegetable Consumption. Nutrition Reviews, 59, 224-235. https://doi.org/10.1111/j.1753-4887.2001.tb07014.x

[13] Pearson, N., Biddle, S.J.H. and Gorely, T. (2009) Family Correlates of Fruit and Vegetable Consumption in Children and Adolescents: A Systematic Review. Public Health Nutrition, 12, 267-283. https://doi.org/10.1017/S1368980008002589

[14] Di Noia, J. and Byrd-Bredbenner, C. (2014) Determinants of Fruit and Vegetable Intake in Low-Income Children and Adolescents. Nutrition Reviews, 72, 575-590. https://doi.org/10.1111/nure.12126

[15] Krølner, R., Rasmussen, M., Brug, J., Klepp, K.-I., Wind, M. and Due, P. (2011) Determinants of Fruit and Vegetable Consumption among Children and Adolescents: A Review of the Literature. Part II: Qualitative Studies. International Journal of Behavioral Nutrition and Physical Activity, 8, 112. https://doi.org/10.1186/1479-5868-8-112

[16] Peltzer, K. and Pengpid, S. (2010) Fruits and Vegetables Consumption and Associated Factors among In-School Adolescents in Seven African Countries. International Journal of Public Health, 55, 669-678.

https://doi.org/10.1007/s00038-010-0194-8

[17] Drewnowski, A., Mennella, J.A., Johnson, S.L. and Bellisle, F. (2012) Sweetness and Food Preference. Journal of Nutrition, 142, 1142S-1148S. https://doi.org/10.3945/jn.111.149575

[18] Delisle, H. (2010) Findings on Dietary Patterns in Different Groups of African Origin Undergoing Nutrition Transition. Applied Physiology, Nutrition, and Metabolism, 35, 24-28.

[19] Tiedje, K., Wieland, M.L., Meiers, S.J., Mohamed, A.A., Formea, C.M., Ridgeway, J.L., et al. (2014) A Focus Group Study of Healthy Eating Knowledge, Practices, and Barriers among Adult and Adolescent Immigrants and Refugees in the United 
States. International Journal of Behavioral Nutrition and Physical Activity, 11, 63. https://doi.org/10.1186/1479-5868-11-63

[20] Banna, J.C., Gilliland, B., Keefe, M. and Zheng, D. (2016) Cross-Cultural Comparison of Perspectives on Healthy Eating among Chinese and American Undergraduate Students. BMC Public Health, 16, 1015.

https://www.ncbi.nlm.nih.gov/pmc/articles/PMC5037860/

[21] Zarnowiecki, D.M., Parletta, N. and Dollman, J. (2016) Socio-Economic Position as a Moderator of 9-13-Year-Old Children's Non-Core Food Intake. Public Health Nutrition, 19, 55-70. https://doi.org/10.1017/S1368980015001081

[22] Zarnowiecki, D.M., Dollman, J. and Parletta, N. (2014) Associations between Predictors of Children's Dietary Intake and Socioeconomic Position: A Systematic Review of the Literature. Obesity Reviews, 15, 375-391.

https://doi.org/10.1111/obr.12139 